\title{
UNAS POCAS PALABRAS PRELIMINARES
}

El volumen que el lector tiene entre sus manos recoge trabajos de muy distinta procedencia. La mayoría de ellos son aportaciones críticas sobre dos ámbitos calderonianos bien diferenciados. El primero tiene estrecha relación con sus autos sacramentales. Y se publican en este número diferentes contribuciones debatidas en el Congreso Internacional, celebrado en Pamplona, los días 16 y 17 de diciembre del pasado año: «Ingenio, teología y drama en los autos de Calderón», organizado por el GRISO de la Universidad de Navarra, en el marco del proyecto de autos sacramentales financiado por la Subdirección General de Proyectos de Investigación (FFI2008-02319/FILO) cofinanciado por el FEDER, y de las acciones complementarias a proyectos de investigación fundamental no orientada (Convocatoria 2010) (FFI2010-10859) del Ministerio de Ciencia e Innovación del Gobierno de España. También contó con el patrocinio de TC-12, Programa Consolider-Ingenio 2010, CSD2009-00033, del Plan Nacional de Investigación Científica, Desarrollo e Innovación Tecnológica ${ }^{1}$.

A dicho congreso concurrieron especialistas calderonianos que disertaron sobre el complejo y rico mundo del auto sacramental.

${ }^{1}$ A estos dos proyectos pertenecen varios trabajos publicados en este volumen: los de Enrique Duarte, Luis Galván, Mariela Insúa, Carlos Mata y Rafael Zafra. Los autores agradecen el apoyo de las citadas instituciones y programas de investigación. 
Otra buena parte de las contribuciones que presenta este número del Anuario calderoniano tiene que ver con ese otro mundo calderoniano, más profano: el de sus comedias y tragedias, y se recogen aquí parte de las intervenciones que los especialistas más reputados del ámbito hispánico pudieron aportar en el seminario calderoniano organizado por el GIC (Grupo de Investigación Calderoniana) de la Universidad de Santiago de Compostela bajo la dirección de Luis Iglesias Feijoo y Santiago Fernández Mosquera que se celebró a mediados de junio de1 2010 .

\section{Pero dejemos ya los preámbulos, y que hablen los textos.}
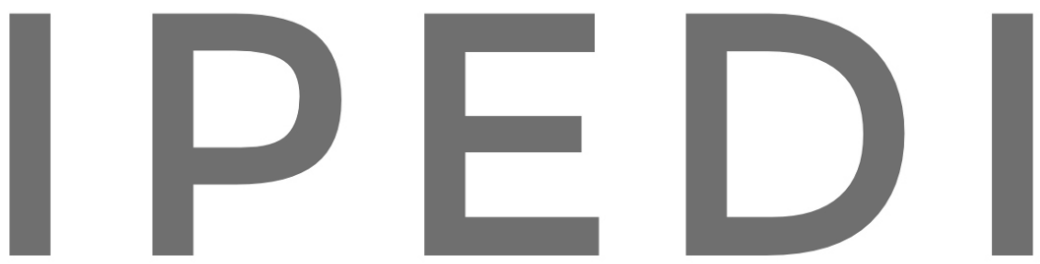